\title{
Synthesis And Evaluation Of Wound Healing Properties of HyDrO-DiAb Hydrogel Loaded With Green-Synthetized AGNPS: In Vitro And In Ex Vivo Studies
}

\section{Mariarosa Ruffo}

Universita della Calabria Dipartimento di Farmacia e Scienze della Salute e della Nutrizione Ortensia llaria Parisi

Universita della Calabria Dipartimento di Farmacia e Scienze della Salute e della Nutrizione

Marco Dattilo

Universita della Calabria Dipartimento di Farmacia e Scienze della Salute e della Nutrizione

Francesco Patitucci

Universita della Calabria Dipartimento di Farmacia e Scienze della Salute e della Nutrizione

Rocco Malivindi

Universita della Calabria Dipartimento di Farmacia e Scienze della Salute e della Nutrizione

\section{Vincenzo Pezzi}

Universita della Calabria Dipartimento di Farmacia e Scienze della Salute e della Nutrizione

\section{Tzanko Tzanov}

Polytechnic University of Catalonia: Universitat Politecnica de Catalunya

Francesco Puoci ( $\nabla$ francesco.puoci@unical.it)

Universita della Calabria Dipartimento di Farmacia e Scienze della Salute e della Nutrizione

\section{Research Article}

Keywords: Diabetic Foot Ulcerations (DFUs), Silver Nanoparticles, Green-synthesis, Hydrogel, Wound Healing.

Posted Date: August 5th, 2021

DOl: https://doi.org/10.21203/rs.3.rs-627032/v1

License: (9) (1) This work is licensed under a Creative Commons Attribution 4.0 International License. Read Full License 
Version of Record: A version of this preprint was published at Drug Delivery and Translational Research on March 31st, 2022. See the published version at https://doi.org/10.1007/s13346-022-01121-w. 


\title{
SYNTHESIS AND EVALUATION OF WOUND HEALING PROPERTIES OF HYDRO-DIAB HYDROGEL LOADED WITH GREEN-SYNTHETIZED AGNPS: IN VITRO AND IN EX VIVO STUDIES
}

\author{
Mariarosa Ruffo ${ }^{1,2}$; Ortensia Ilaria Parisi ${ }^{1,2}$; Marco Dattilo ${ }^{1}$; Francesco Patitucci ${ }^{1,2}$; Rocco Malivindi ${ }^{1,2}$; \\ Vincenzo Pezzi ${ }^{1,2}$; Tzanko Tzanov ${ }^{3}$ and Francesco Puoci ${ }^{1,2^{*}}$
}

\begin{abstract}
${ }^{1}$ Department of Pharmacy, Health and Nutritional Sciences, University of Calabria, 87036 Rende (CS), Italy; ${ }^{2}$ Macrofarm s.r.l., c/o Department of Pharmacy, Health and Nutritional Sciences, University of Calabria, 87036; ${ }^{3}$ Molecular and Industrial Biotechnology group, Department of Chemical Engineering, Polytechnic University of Catalonia, Terrassa, Spain
\end{abstract}

\begin{abstract}
*francesco.puoci@unical.it
Abstract

In diabetic patients, the presence of neuropathy, peripheral vascular diseases and ischemia, leads to the formation of foot ulcerations with a higher risk of infection because the normal response to bacterial infection is missing. In the aim to control and treat Diabetic Foot Ulcerations (DFUs), wound dressings able to absorb exudate, to prevent infections and to promote wound healing, are needed. For this reason, the aim of the present research was to synthetize a biocompatible hydrogel composed by Carboxymethylcellulose (HyDrO-DiAb) loaded with Silver nanoparticles (AgNPs) for the treatment of diabetic foot ulcer. In this study, AgNPs were obtained by a green synthesis and, then, were dissolved in CMC hydrogel that, after freeze drying process become a flexible and porous structure. The in vitro and in $e x$-vivo wound healing activity of the obtained HyDrO-DiAb hydrogel was evaluated.
\end{abstract}

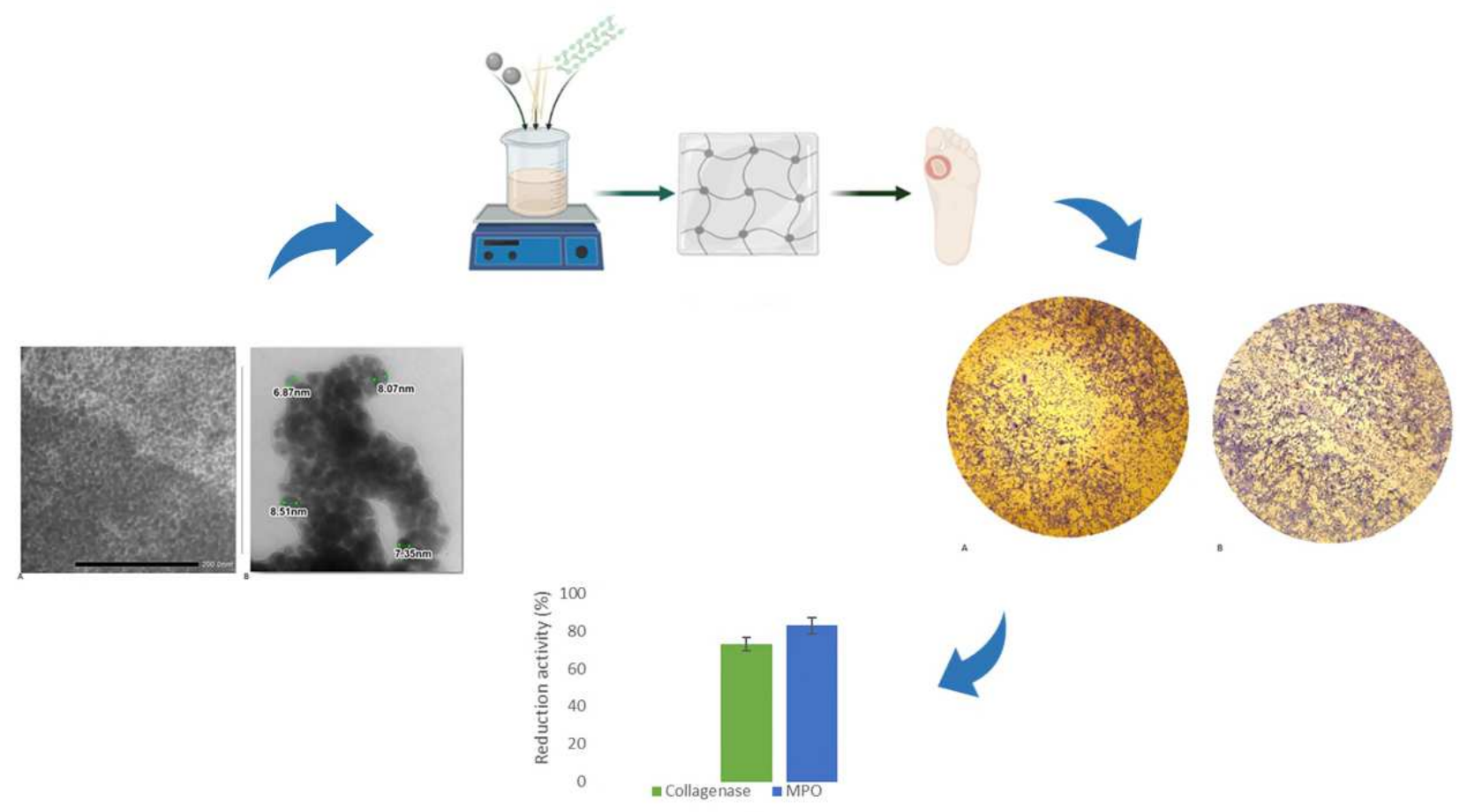

Keywords: Diabetic Foot Ulcerations (DFUs), Silver Nanoparticles, Green-synthesis, Hydrogel, Wound Healing. 


\section{Introduction}

Chronic high blood glucose presents in diabetic patients increases the risk of developing complications such as heart disease, stroke, blindness, kidney disease and foot complications [1]. Diabetic foot ulcer (DFU), moreover, represents one of the most severe and intractable complication of diabetes and, furthermore, appears in association with neuropathy and ischemia [2]. In most cases, healing of DFUs is a slow process and, for this reason, the presence of infection and heavy exudate causes gangrene and amputation [3]. Among factors that cause a resistance of wound healing, the disfunction of resident cells represent one of the major causes. Cells like keratinocytes, fibroblasts, macrophages, and lymphocytes are important because are able to regulate different stages of wound healing, allow the eradication of bacteria and facilitate the formation of epithelial tissue [4]. In the aim to manage chronic wounds like DFUs, wound dressings should be able to absorb exudate, to protect wounds from bacterial infection and to support regeneration and repair of epithelial tissue by providing a suitable environment [5]. Furthermore, to avoid trauma on the wound site, an ideal wound dressing should be non-adherent and ease to apply and to remove. For this purpose, hydrogels, which are non-toxic and non-adherent, represent an ideal material for wound healing [6]. The ability to contain high levels of water and the well-known swelling capacity, allow the hydrogel to maintain a moist environment to the wound and, at the same time, to absorb exudate in the wound site [7]. Carboxymethylcellulose (CMC), is well known for its water absorbing, for its swelling ability and for its biocompatibility [8]. For this reason, CMC may be used for the treatment of severe wounds and, in particular, can be used for the preparation of hydrogel in the treatment of chronic wounds like diabetic foot ulcers. Hydrogel loaded with silver nanoparticles (AgNPs) represents a promising strategy in the treatment of chronic wound like DFUs.

AgNPs are well known as antimicrobial agents thanks to their antibacterial, antiviral and antifungal activities [9]. The ability of silver nanoparticles to cause death of Gram-positive, Gram-negative and antibiotic-resistant bacteria makes them a valid broad-spectrum antibacterial agent [10]. Moreover, low citotoxicity and small sizes of AgNPs allow them to damage microbial cell membranes and to cause loss of activity of enzymes, RNA and DNA with consequent bacterial death [11].

AgNPs were synthetized by different methods such as physical, chemical and green synthesis [12]. The last one is on the most preferred because, if compared to physical and chemical methods, it is no expensive and ecofriendly [13] and, nanoparticles, are obtained from natural extracts [14].

In this study, Olive Leaves dry extract and Camellia Sinensis leaves dry extract were used to obtain AgNPs that were loaded in hydrogel composed by CMC to use in the treatment of chronic wounds like DFUs. The obtained nanoparticles were characterized by UV-Vis absorption spectroscopy, Dynamic Light Scattering (DLS) and Transmission Electron Microscopy (TEM). Once dimensions and shapes were evaluated, its phenolic content was determined. The obtained nanoparticles were loaded in a hydrogel composed by CMC and the obtained hydrogel (HyDrO-DiAb) was studied. In the aim to evaluate the possible use of HyDrO-DiAb as wound dressing in the treatment of DFUs, its swelling ability, water retention capacity, anti-inflammatory, antimicrobial and antioxidant activity were evaluated. Furthermore, the in vitro ability to close a wound and in ex-vivo ability to inhibit deleterious wound enzyme were studied.

\section{Materials and methods}

\section{Materials}

Reagents were purchased from Sigma-Aldrich (Milan, Italy). Camellia Sinensis leaf dry extract and Olive leaves dry extract were supplied by Macrofarm srl. The EPISKINTM RHE/L/13 human skin equivalent kit was obtained from SkinEthic Laboratories (Lyon, France). All solvents were reagent or HPLC grade. EnzChek Gelatinase/Collagenase Assay Kit was provided by Life Technologies (Spain). THP-1 human monocytic leukemia cell line from ATCC was used to in vitro evaluate if tested sample is a skin sensitizer or non- 
sensitizer. Cells were kept in RPMI containing 10\% fetal bovine serum (FBS), $0.05 \mathrm{mM}$ 2-mercaptoethanol, 100 units $/ \mathrm{mL}$ penicillin, and $100 \mu \mathrm{g} / \mathrm{mL}$ streptomycin.

3T3-L1 cells were purchased from ATCC (CL-173) and incubated at $37{ }^{\circ} \mathrm{C}$ with $5 \% \mathrm{CO}_{2}$ in Dulbecco's Modified Eagle Medium (DMEM), 10\% bovine calf serum (BCS) and 1\% penicillin/streptomycin.

\section{Methods}

\section{Preparation of Olive Leaves and Camellia Sinensis extract}

In the aim to obtain an aqueous extract by using Olive Leaves dry extract and Camellia Sinensis dry extract, the amount of $2.5 \mathrm{~g}$ of Olive Leaves and $1.25 \mathrm{~g}$ of Camellia Sinensis dry extract were dissolved in $100 \mathrm{ml}$ of distilled water at $50^{\circ} \mathrm{C}$ and under stirring for 30 minutes. At the end of extraction time, the obtained aqueous extract (Cs-OLE extract) was filtered by using the Whatman No. 1 filter paper and stored at $4^{\circ} \mathrm{C}$ for further analysis.

\section{Characterization of the obtained extract}

According to the literature [15], the phenolic content of Cs-OLE extract was evaluated by using FolinCiocalteu method. $2 \mathrm{ml}$ of the obtained extract were mixed with $2 \mathrm{ml}$ of Folin-Ciocalteu reagent and $2 \mathrm{ml}$ of sodium carbonate solution $(7.5 \% \mathrm{w} / \mathrm{v})$. The obtained mix reaction was shaken and incubated for 2 hours at room temperature. Finally, the absorbance of mix reaction was measured at $760 \mathrm{~nm}$ by using a control prepared in the same conditions, but without extract, and with $2 \mathrm{ml}$ of distilled water which replaces it. The amount of total phenolic compounds was expressed as $\mathrm{mg}$ of Gallic Acid equivalent per $\mathrm{g}$ of extract (mgGAE/g). The equation obtained from calibration curve of Gallic Acid was used to quantify the amount of total phenolic compounds present in Cs-OLE extract.

\section{Green-Synthesis and purification of AgNPs}

To synthesize AgNPs, $20 \mathrm{ml}$ of Cs-OLE extract was mixed with a solution of $\mathrm{AgNO}_{3} 0.01 \mathrm{M}$ in a pH of reaction mixture of 8 [16]. The solution was mixed for 20 minutes at room temperature and, at the end of this time, the nanoparticles solution was centrifuged at $10.000 \mathrm{rpm}$ for 30 minutes at room temperature. The collected pellets were washed three times and then, freeze-dried.

\section{Characterization of the obtained AgNPs}

To monitoring the surface plasmon resonance, the obtained AgNPs were characterized by using Thermo Scientific Evolution $201 \mathrm{UV}-\mathrm{Vis}$ in the spectral window of $200-800 \mathrm{~nm}$. To evaluate the surface potential and hydrodynamic size, the obtained AgNPs were first diluted in water and then, sonicated. The obtained AgNPs suspension was analyzed by using zeta sizer Particles Size Analyzer 90 Plus (Brookhaven Instrument Corporation, New York, NY, USA). Finally, the morphology and distribution of synthetized AgNPs were further examined with high resolution TEM (JEM-1409Plus).

The phenolic content of AgNPs was evaluated by using Folin-Ciocalteu method [15]. $10 \mathrm{mg}$ of the obtained nanoparticles were mixed with $2 \mathrm{ml}$ of distilled water, $2 \mathrm{ml}$ of Folin-Ciocalteu reagent and $2 \mathrm{ml}$ of sodium carbonate solution $(7.5 \% \mathrm{w} / \mathrm{v})$. After 2 hours of incubation at room temperature, the absorbance was measured at $760 \mathrm{~nm}$ and the obtained data were expressed as $\mathrm{mg}$ of Gallic Acid equivalent per $\mathrm{g}$ of nanoparticles (mgGAE/g).

\section{Preparation and characterization of HyDrO-DiAb}

For the preparation of hydrogel, CMC was dissolved in water in a concentration of $2 \% \mathrm{w} / \mathrm{v}$ and left under stirring for 30 minutes at room temperature. After the dissolution of CMC, AgNPs $(0.01 \% \mathrm{w} / \mathrm{w})$ were 
dissolved in the solution and maintained at room temperature for 6 hours under stirring. After that, citric acid, as crosslinking agent, was added and, the obtained mix reaction, was incubated for further 6 hours at room temperature. To obtain the final hydrogel loaded with AgNPs, the prepared solution was freeze-dried and then, stored at room temperature for further analysis.

To evaluate swelling ability of HyDrO-DiAb, $30 \mathrm{mg}$ of tested sample were placed into a tared $5 \mathrm{~mL}$ sintered glass filter ( $10 \mathrm{~mm}$; porosity, G3), weighed, and left to swell in an alkaline PBS (pH 8) to mime chronic wound conditions [17]. The filter was left in PBS for 24 hours and, after that, the excess of the solution was removed by percolation, centrifugated at $2000 \mathrm{rpm}$ for $10 \mathrm{~min}$ and, finally, weighed. The filter tare was measured after centrifugation with only water. The water content percentage (WR\%) was calculated at different time intervals according to Equation (1):

$$
W R \%=\frac{W s-W d}{W d} \times 100
$$

where Ws was weight of swollen hydrogel, while Wd was weight of dried hydrogel. Each experiment was carried out three times.

Once swollen, the hydrogel was used to evaluate water retention capacity. The swollen sample was incubated at $37^{\circ} \mathrm{C}$ with $70-75 \%$ relative humidity and water retention capacity was measured using Equation (2):

$$
R w=\frac{W t}{W 0} \times 100
$$

Where $\mathrm{W}_{\mathrm{t}}$ is weight of sample at different time intervals and $\mathrm{W}_{0}$ is weight of sample before incubation.

To in vitro evaluate release of AgNPs from tested sample, the amount of $50 \mathrm{mg}$ of HyDrO-DiAb was immersed in $6 \mathrm{~mL}$ of PBS (0.1 M, pH 8) and placed in a dialysis bag, which was sealed at each end with clamps [18].

The dialysis tube was immersed in a flask containing $40 \mathrm{ml}$ of the same PBS and incubated for 8 hours at $37^{\circ} \mathrm{C}$ $\pm 0.5^{\circ} \mathrm{C}$ in constant agitation in a water bath.

The amount of $1 \mathrm{ml}$ of sample was withdrawn and, at selected time intervals of 1, 2, 4, 6 and 8 hours was replaced by the same volume of fresh PBS. The amount of released AgNPs was quantified spectrophotometrically at $430 \mathrm{~nm}$, by using the equation obtained from calibration curve of AgNPs. All experiments were carried out in triplicates.

\section{Wound healing scratch assay}

The wound healing ability of HyDrO-DiAb was assessed by wound healing scratch assay [19]. 3T3-L1 cells were seeded on 6-well plates at a density of $5 \times 10^{5}$ cells/well and incubated for $24 \mathrm{~h}$ in an incubator at $37^{\circ} \mathrm{C}$ under a $\mathrm{CO}_{2}(5 \%)$ atmosphere. Wound healing scratch assay was performed by using a p200 pipet trip which scraped the cell monolayer creating a "scratch" [19]. The debris were removed by washing cells with PBS which were, then, replaced with $2 \mathrm{ml}$ of culture medium containing $100 \mu \mathrm{g} / \mathrm{ml}$ of HyDrO-DiAb. Wells in which hydrogel was not incubated, were used as control. After 24 hours of incubation, cells were stained with Coomassie blue brilliant and scratched area was visualized with a microscope (Olympus ckx53) under phasecontrast optics ( $\times 4$ magnification). The percentage of wound closure was calculated using the Image $\mathbf{J}$ software and expressed as reported in the equation (3):

$$
\text { Wound clousure }(\%)=\frac{A_{t}-A_{0}}{A_{t}} \times 100
$$

Where $A_{0}$ is the area of is the area of the wound measured immediately after scratching and $A_{t}$ is the area of the wound measured after 24 hours. 


\section{Minimum Inhibitory Concentration (MIC)}

The evaluation of MIC (the lowest concentration of the formulation at which the organisms does not demonstrate visible growth) of HyDrO-DiAb was determined against S. aureus (ATCC6538), E. coli (ATCC8739) and P. aeruginosa (ATCC9027). In each sterile tube different concentrations of tested sample (from 0.1 to $50 \mu \mathrm{g} / \mathrm{ml}$ ) were added to TSB (Tryptone Soy Broth) and to $100 \mu \mathrm{L}$ of adjusted bacterial solution $\left(\mathrm{CFU} \sim 10^{7}\right)$. Turbidity in the tested tubes indicated the growth of microorganisms and, so, MIC is considered the lowest concentration of hydrogel that causes color change [20].

\section{In vitro antioxidant activity}

The antioxidant activity of the HyDrO-DiAb was tested using DPPH ((2,2-diphenyl-1-picryl-hydrazylhydrate) and ABTS (2,2'-azino-bis (3-ethylbenzothiazoline-6-sulphonic acid) radical scavenging assays [21]. For DPPH radical scavenging assay, $30 \mathrm{mg}$ of tested hydrogel were added to $1 \mathrm{ml}$ of distilled water and to 4 $\mathrm{ml}$ of an ethanolic solution of the enzyme $(200 \mu \mathrm{M})$. Finally, in the aim to obtain a final volume of $10 \mathrm{ml}$, ethanol was added to the mix reaction. The tested sample was incubated at room temperature, in the dark, for 15 minutes. At the end of this time, the residual DPPH concentration was measured at $517 \mathrm{~nm}$ against a control prepared in the same reaction conditions but without hydrogel. The radical scavenging capacity was calculated according to the Equation (4).

The ABTS radical scavenging activity of hydrogel was evaluated by following the literature with some modifications [22]. The amount of $30 \mathrm{mg}$ of tested sample was added to $2 \mathrm{ml}$ of ABTS solution and, the obtained mix reaction was incubated for 6 minutes in the dark, under stirring and at room temperature. At the end of 6 minutes, the absorbance was measured at $734 \mathrm{~nm}$ and the radical scavenging activity was measured according to Equation (4). A control sample was prepared in the same experimental conditions but without hydrogel.

$$
\text { Inhibition }(\%)=\left(\frac{A_{0}-A_{1}}{A_{0}}\right) \times 100
$$

Where $\mathrm{A}_{0}$ is the absorbance of control sample and $\mathrm{A}_{1}$ is the absorbance of HyDrO-DiAb.

\section{In vitro antinflammatory activity}

The anti-inflammatory estimation of HyDrO-DiAb was studied by evaluating the ability of tested sample to inhibit BSA denaturation [23]. $100 \mathrm{mg}$ of tested hydrogel were suspended in $2 \mathrm{ml}$ of a solution of BSA (1 mM) prepared in PBS pH 7.4. In the aim to cause the denaturation of BSA, the mixture was incubated for 30 minutes at $37^{\circ} \mathrm{C}$. The absorbance of reaction was read at $660 \mathrm{~nm}$ and the inhibition of BSA denaturation was estimated using the equation (4).

\section{In $e x$-vivo ability to inhibit wound enzymes}

Wound exudates, which were extracted using the UrgoClean dressing (from Urgo Medical) of a patient with a venous leg ulcer (Hospital de Terrassa (Spain), were used to perform in ex-vivo studies. To obtain wound exudates, $1 \mathrm{~g}$ of dressing sample was soaked in $5 \mathrm{~mL}$ of PBS pH 7.4 for $10 \mathrm{~min}$ [24]. Thereafter, the supernatant was vortexed for 10 minutes at $10.000 \mathrm{rpm}$ at $4{ }^{\circ} \mathrm{C}$ and finally stored in the fridge at $4{ }^{\circ} \mathrm{C}$ for further use.

To evaluate the ability of hydrogel to inhibit in ex vivo MPO activity, the amount of taurine chloramine produced by the MPO/ $\mathrm{H}_{2} \mathrm{O}_{2} / \mathrm{Cl}^{-}$system, was evaluated. To do this, $2 \mathrm{mg}$ of HyDrO-DiAb were mixed with $750 \mu \mathrm{L}$ of PBS (50 mM pH 6.5 with $200 \mathrm{mM}$ of $\mathrm{NaCl}$ and $6.67 \mathrm{mM}$ of taurine), $100 \mu \mathrm{L}$ of $\mathrm{H}_{2} \mathrm{O}_{2}(1 \mathrm{mM})$ and with $150 \mu \mathrm{L}$ of wound fluid diluted 10 times. The enzymatic reaction was incubated for $30 \mathrm{~min}$ at $37^{\circ} \mathrm{C}$ and then, stopped by adding $25 \mu \mathrm{L}(1 \mathrm{mg} / \mathrm{ml})$ of catalase solution. To evaluate the amount of produced taurine 


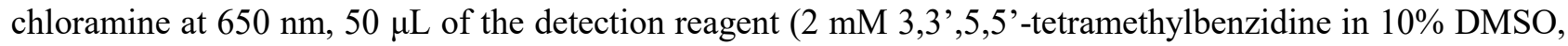
$100 \mathrm{~mL} \mathrm{NaI}$ in $400 \mathrm{mM}$ acetate buffer $\mathrm{pH}$ 5.4) was added to the enzymatic reaction. The obtained results were expressed as percentage of MPO inhibition and were compared to that obtained in a control sample prepared without hydrogel [25].

Fluorescently labeled gelatin substrate ((EnzChek kit, ThermoFisher Scientific) is digested by collagenase which causes the release of a fluorescent peptides that increases fluorescence of the supernatant. In the presence of an inhibitor of collagenase, gelatin is not digested and, consequently, there is a decrease in fluorescence value of the supernatant.

The ability of HyDrO-DiAb to inhibit collagenase was performed by incubating $30 \mathrm{mg}$ of sample with 400 $\mu \mathrm{L}$ of wound fluid, previously diluted 2 times.

The mix reaction was left for $24 \mathrm{~h}$ at $37^{\circ} \mathrm{C}$ and, at the end of this time, $100 \mu \mathrm{L}$ of incubated sample was transferred to a 96 -well plate and was mixed with $80 \mu \mathrm{L}$ of buffer. $20 \mu \mathrm{L}$ of gelatin substrate $(250 \mu \mathrm{g} / \mathrm{ml})$ were added in each well and the change of fluorescence was monitored at excitation/emission 493/528 nm. Sample without hydrogel was used as a control and the collagenase activity in it was considered as $100 \%$ [25].

\section{Cell viability assay}

Cell viability studies were assessed using MTT assay on 3T3 L1 cell line. In the performed study the reduction of yellow 3-(4, 5-dimethyl thiazol-2-yl)-2, 5-diphenyl tetrazolium bromide (MTT) by mitochondrial succinate dehydrogenase, which can only occur in metabolically active cells, [26] was evaluated. Briefly, cells were seeded in 96-well plates at $1 \times 10^{4}$ cells/well and maintained at $37^{\circ} \mathrm{C}$ with $5 \% \mathrm{CO}_{2}$ in $\mathrm{DMEM}$ containing $10 \%$ bovine calf serum (BCS) and 1\% penicillin/streptomycin. Then, medium was removed and replaced with a fresh one containing different concentrations of HyDrO-DiAb $(45-100 \mu \mathrm{g} / \mathrm{ml})$. After 24 hours of incubation, cells viability was determined by adding $10 \mu \mathrm{L}$ of MTT solution $(1 \mathrm{mg} / \mathrm{ml})$ to each well. After 1 hour of incubation at $37^{\circ} \mathrm{C}$ in an atmosphere containing $5 \% \mathrm{CO}_{2}, 100 \mu \mathrm{L}$ of DMSO for formazan crystal solubilization, were added. After 10 minutes of incubation in dark conditions, the absorbance of reduced MTT was evaluated at $570 \mathrm{~nm}$ in a microplate reader (Synergy h1 Hybrid reader Biotek). Cell viability was expressed as a percentage compared to control wells.

\section{In vitro skin sensitization (h-CLAT) OECD 442E}

The purpose of the test human Cell Line Activation test (h-CLAT) is to evaluate the sensitizing potential of HyDrO-DiAb, in accordance with the method described in OECD 442E and in the 158 EURL-ECVAM protocol (European Union Reference Laboratory for alternatives to animal testing). In this study, a monocytes cell line, named THP-1, was used as prototypic blood-derived immunologically active cells. On these cells, the expression of two co-stimulatory molecules, CD54 and CD86, was tested and, 2,4-dinitrochlorobenzene (DNCB), a well-known contact sensitizing agent, was used as a positive control. An increased expression of CD54 and CD86 on monocytes is a signal of activation of the immune response, derived from the exposition to potentially sensitizing contact allergens. In the performed test, human monocytic leukemia cell line named THP-1 (ATCC TIB-202) were kept in RPMI containing 10\% FBS, $0.05 \mathrm{mM}$ 2-mercaptoethanol, 100 units/ml penicillin and $100 \mu \mathrm{g} / \mathrm{ml}$ streptomycin. To evaluate their reactivity, THP-1 cells were exposed to DNCB and nickel sulphate, which were used as positive controls, and to lactic acid, which was used as a negative control. Once their reactivity was evaluated, cells were seeded in a 96- well flat-bottom plate at a density of $1.6 \times 10^{5}$ cells/well and, after 24 hours, the culture medium was mixed 1:1 with the tested hydrogel and controls. Culture medium was used as negative control. At the end of incubation time, cells were centrifugated and re-suspended in a Flow Cytometry Staining Buffer (FACS Buffer) which contained iodure propidium (PI) for cytometry analysis. The concentration that caused $25 \%$ of cell mortality (CV75 value) was calculated and used as the highest concentration in the final test. 
Once estimated CV75 value, HyDrO-DiAb was solubilized in phosphate buffer at the concentration corresponding to 100 -fold the $1.2 \mathrm{CV} 75$. Then, to obtain different stock solutions ranging from $0.335 \mathrm{x}$ CV75 to $1.2 \times$ CV75, 1:1.2 serial dilutions are made. The obtained stock solutions were diluted 1:50 into culture medium and, finally, a further 1:2 dilution factor was used for the h-CLAT test. In the cited test, culture medium and DNCB $(4 \mu \mathrm{g} / \mathrm{ml})$ were used as negative and positive controls, respectively. Cells were exposed to the tested sample for $24 \mathrm{~h}$ at $37^{\circ} \mathrm{C}$ with $5 \% \mathrm{CO}_{2}$ and, at the end of incubation time, they were centrifugated, resuspended in FACS buffer and divided into three aliquots. Three aliquots of cells were, furthermore, centrifugated, resuspended in FACS buffer containing $0.01 \%$ of gamma globulins and incubated at $4^{\circ} \mathrm{C}$ for 15 minutes. At the end of incubation time, cells were centrifugated and incubated with a fluoresceinated antiCD86, anti-CD54 or mouse IgG1 (control isotype) antibodies for $30 \mathrm{~min}$ at $4^{\circ} \mathrm{C}$.

Finally, cells were washed with FACS buffer and resuspended in the same buffer in the presence of PI solution. Cell viability and the expression levels of CD86 and CD54 were analyzed with flow cytometry. Cell viability was calculated using the following equation (5):

$$
\text { Cell viability }(\%)=\left(\frac{\text { Living cells }}{\text { Acquired cells }}\right) \times 100
$$

The concentration that showed $75 \%$ of THP-1 cell survival (CV75) was calculated by using the following equation (6)

$$
\log C V 75=\frac{(75-B) x \log (C)-(75-A) \times \log (D)}{A-B}
$$

Where: $\mathrm{A}$ is cell viability $>75 \%$; $\mathrm{B}$ is cell viability $<75 \%$; $\mathrm{C}$ or $\mathrm{D}$ is the concentration showing the value of cell viability A or B. The obtained CV75 value was used to define the highest concentration of tested hydrogel that can be used for the measurement of CD86/CD54 expression in the final test. After treatment of cells with tested sample, the expression of CD86 and CD54 was analyzed by flow cytometry. The relative fluorescence intensity (RFI) of CD86 and CD54 for positive control and hydrogel treated cells, respectively, was calculated according to the following equation (7), where MFI is the mean fluorescence intensity that is proportional to the expression of co-stimulatory molecules:

$$
\mathrm{RFI}=\frac{\text { MFI of sample with cells }- \text { MFI of sample with isotype cells }}{\text { MFI of solvent with cells }- \text { MFI of solvent with isotype cells }}
$$

\section{In vitro skin irritation OECD 439}

To predict skin irritation of chemicals, which causes a decrease in cell viability, Reconstructed Human Epidermis Test Method (OECD 439) was used [27]. The EpiDerm ${ }^{\mathrm{TM}}$ reconstructed human epidermal (RhE) plate was equilibrated overnight at $37^{\circ} \mathrm{C}$ and $5 \% \mathrm{CO}_{2}$ in a humidified incubator. Then, $25 \mathrm{mg}$ of HyDrO-DiAb were applied directly to the top of the epidermis surface and, its effect, was compared to that obtained from Sodium Dodecyl Sulphate SDS (5\%) and PBS which were used as positive and negative controls, respectively. After 60 minutes of contact between RhE and tested sample, tissues were rinsed with PBS, transferred into 2 $\mathrm{ml}$ of fresh medium and incubated for 42 hours. All tests were performed thrice. At the end of incubation time, tissue viability was assessed by MTT reduction measurement. To do this, RhE tissues were transferred into a 24-well plate in which MTT medium $(1 \mathrm{mg} / \mathrm{mL})$ was added. The tested plate was placed in a humidified incubator $\left(37{ }^{\circ} \mathrm{C}, 5 \% \mathrm{CO}_{2}\right)$ for 3 hours and, at the end of this time, RhE tissues were removed from MTT medium. To extract formazan salt, tissues were transferred in a 24 well-plate containing $2 \mathrm{ml}$ of isopropanol and then, shaken at $120 \mathrm{rpm}$ at room temperature for $2 \mathrm{~h}$. The amount of $200 \mu \mathrm{L}$ of each extraction solution was transferred into a 96 well plate and the optical density (OD) of the extracted formazan was determined at $570 \mathrm{~nm}$ using a microplate reader (Synergy h1 Hybrid reader Biotek). Isopropanol was used as a blank vehicle. Cell viability was expressed as percentage and calculated using the following equation (8). 


$$
\text { Viability }(\%)=\frac{(\text { OD sample } x 100)}{\text { OD negative control }}
$$

\section{Results and Discussion}

\section{Preparation and characterization of the extract}

Among the plant extracts which could be used for green synthesis of AgNPs, Camellia sinensis and Olive Leaves extract can be considered a perfect mix, thanks to their polyphenolic composition.

Camellia sinensis leaves dry extract is rich in polyphenolic compounds such as Catechins which represent the $70-80 \%$ of total polyphenols [28]. Catechins present in tea leaves are characterized by polymeric and monomeric catechins, condensed tannins, proanthocyanidins and catechin derivatives [29]. Considering the total catechin content, 50-80\% is represented by Epigallocatechin-3-gallate (EGCG) while, the remaining part is represented by other catechins such as epicatechin-3-gallate (ECG), epigallocatechin (EGC) and epicatechin (EC) . The other important components of green tea are falvonols which contribute to the antioxidant property of Camellia sinensis leaves [30].

Olive leaves from Calabrian Olea europaea L. , the other plant chosen for green synthesis of AgNPs, present a high concentration of phenolic compounds and several types of flavonoids which are well known to have antioxidant properties [31]. The phenolic compounds present in olive leaves are classified into acids, flavonoids and secoiridoids. The latter are the component present in higher concentration and, among these, Oleuropein is the first secoiridoid isolated from olive leaves followed by its derivatives such as hydroxytyrosol and tyrosol.

Camellia sinensis leaves and Olive leaves dry extracts were used to obtain an aqueous extract (Cs-OLE extract) with a high concentration of phenolic compounds able to reduce $\mathrm{Ag}^{+}$in $\mathrm{Ag}^{0}$ (31).

The phenolic content of Cs-OLE extract, used to synthesize AgNPs, was measured by the Folin-Ciocalteu method and the obtained results evidence a concentration of phenolic compounds of $15 \pm 0.5 \mathrm{mg} \mathrm{GAE} / \mathrm{g}$ of extract.

\section{Green synthesis and characterization of AgNPs}

In the present study, AgNPs were synthesized by the reduction of silver ions in the presence of Cs-OLE extract characterized by a high concentration of phenolic compounds. Indeed, thanks to their well-known antioxidant activity, phenolic compounds could be used to reduce silver ions $\left(\mathrm{Ag}^{+}\right)$to metallic ions $\left(\mathrm{Ag}^{0}\right)$. To do this, 20 $\mathrm{ml}$ of the extract were mixed with a solution of $\mathrm{AgNO}_{3} 0.01 \mathrm{M}$ in a pH of reaction mixture of 8, for 20 minutes and at room temperature. At the end of reaction time, the formation of AgNPs was confirmed by the formation of a yellowish-brown color (Figure 1) caused by excitation of surface plasmon resonance (SPR) [32].

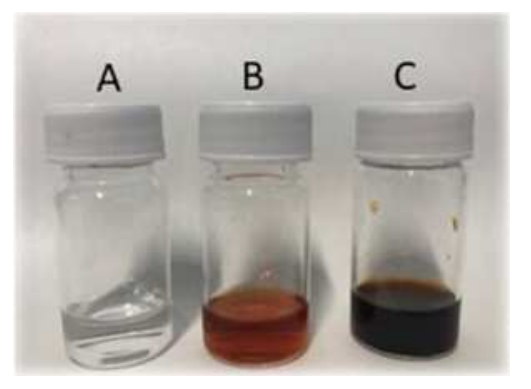

Figure 1: $\mathrm{AgNO}_{3} 0.01 \mathrm{M}(\mathrm{A})$, Cs-OLE extract(B), $\mathrm{AgNPs}(\mathrm{C})$

AgNPs, in fact, present a particular optical phenomenon (SPR) due to their conduction electrons on metal surface which undergo a collective oscillation when they are excited by light in a specific wavelength [33]. Size, shape and type of synthetized nanoparticles influence SPR band which appears in the range of 400-500 
$\mathrm{nm}$ in UV-Vis spectroscopy [34]. In this study, the SPR band of green-synthetized AgNPs was obtained around $430 \mathrm{~nm}$ (Figure 2) with an absorbance of 0.34 after a dilution of 1:10 with water. Previous studies suggested that UV-Visible absorption spectrum of AgNPs is sensitive to their formation and that the value of absorbance is influenced by particle diameter and shape [35] and, in particular, nanoparticles with small diameters present a larger absorption value.

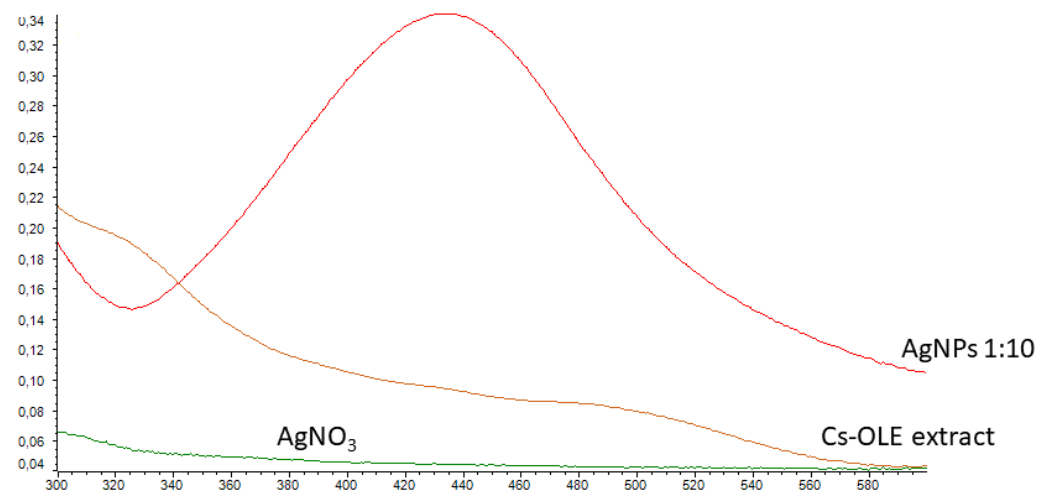

Figure 2: UV-Vis absorption spectra of AgNO3, Cs-OLE extract and synthetized AgNPs (diluted 1:10)

In the aim to evaluate size, shape and dimension of nanoparticles, TEM and DLS instruments were used. TEM images (Figure 3) showed monodisperse AgNPs with a spherical shape and without phenomenon of agglomeration which is characteristic of AgNPs synthetized with a plant extract [36] that prevents aggregation of particle. The obtained AgNPs showed a spherical shape (Figure 3a) with a dimension between 6.87 and $8.51 \mathrm{~nm}$ (Figure $3 b)$.
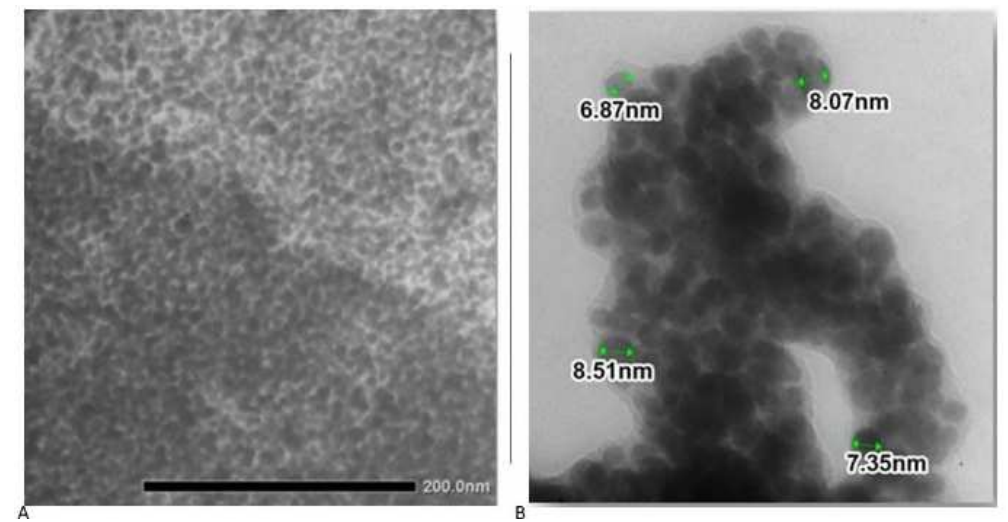

Figure 3: Morphologies of AgNPs (A) and dimension observed in TEM images (B)

The hydrodynamic size of synthetized AgNPs was measured in solution and the obtained results (Table 1) evidenced that measured size was different from that measured with TEM. This is probably due to the hydration layers on the surface of AgNPs. DLS results confirmed that the obtained nanoparticles were monodisperse with a Polydispersity index of 0.179 .

Table 1: Dynamic Light Scattering measurements of AgNPs

\begin{tabular}{|c|c|c|}
\hline Sample & Mean Diameter (nm) & Polydispersity Index \\
\hline AgNPs & $88 \pm 1.6$ & $0.179 \pm 0.02$ \\
\hline
\end{tabular}


To evaluate the phenolic content of AgNPs and, so, the amount of phenolic compounds that didn't react with $\mathrm{AgNO}_{3}$ in the reduction reaction, Folin-Ciocalteu method was performed. The obtained results showed that the amount of $1.71 \pm 0.02 \mathrm{mg}$ equivalent of Gallic Acid is present in one gram of nanoparticles and, so, phenolic compounds of Cs-OLE extract don't react completely with $\mathrm{AgNO}_{3}$ and confer antioxidant activity to the nanoparticles as will be demonstrated in the further results.

\section{Swelling ability, water retention capacity and studies release of HyDrO-DiAb}

Hydrogels based CMC could be considered a promising material for chronic wounds therapy since exhibit important swelling properties which make them a suitable biomimetic environment for cells and tissues. Good swelling properties make hydrogels a perfect medium for sustained and slow release of various therapeutic agents to wound sites such as AgNPs and, at the same time, hydrogels should absorb exudate and maintain a moist wound environment [37]. To evaluate HyDrO-DiAb as a dressing in the treatment of DFUs, in vitro swelling behavior and moisture retention capacity of the prepared hydrogel were evaluated.

The obtained data were compared with those obtained in a hydrogel composed only by CMC.

The obtained results (Figure 4) showed fast rate of absorption in the first 6 hours both for HyDrO-DiAb than for hydrogel composed only with CMC. These data highlighted that the water holding capacity of the tested hydrogels is much higher than their weight and that the addition of AgNPs to the hydrogel of CMC does not modified the hydrophilic nature of the biopolymer.

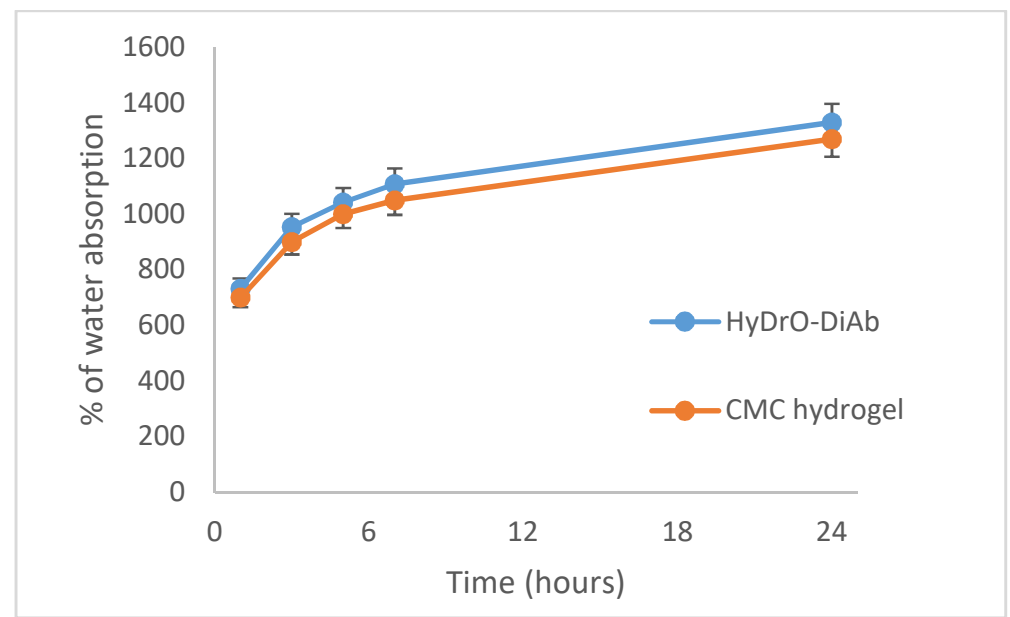

Figure 4: Water absorption capacity of HyDrO-DiAb and CMC hydrogel. All results are reported as mean values \pm SD $(n=3)$.

The ability of wound dressing to retain moist is an important feature to evaluate because epithelial migration and autolytic debridement occur in the presence of an optimal moisture content. Both HyDrO-DiAb than hydrogel composed only by CMC showed a fast decrease in moisture content (Rh) with a total loss of water of 70-80\% after 24 hours (Figure 5). The obtained results evidenced the ability of the prepared hydrogel to retain moisture and, so, its possible use as wound dressing 


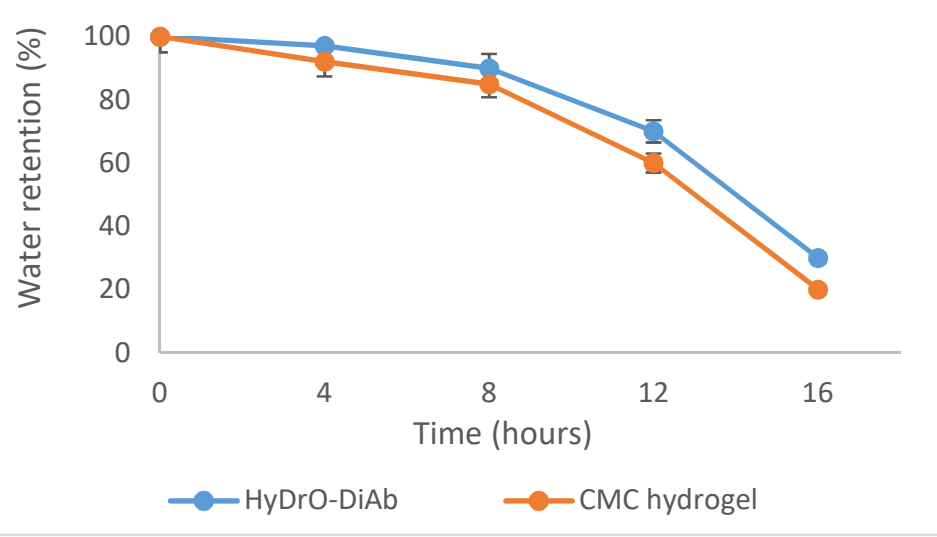

Figure 5: Water retention capacity of HyDrO-DiAb and CMC hydrogel. All results are reported as mean values \pm SD $(n=3)$.

The high-water absorption capacity of the tested hydrogel makes it a perfect medium for sustained and slow release of AgNPs to wound sites and, for this reason, the amount of released AgNPs from hydrogel was tested at different times. The obtained results (Figure 6) showed that nanoparticles were released in a slow and sustained manner for 8 hours and, so, this hydrogel can work as a carrier of AgNPs.

In the first 2 hours there was a burst release of AgNPs with the $71.5 \pm 0.5 \%$ of total released AgNPs characterized, then, by a slow release with $90 \pm 0.1 \%$ of released nanoparticles.

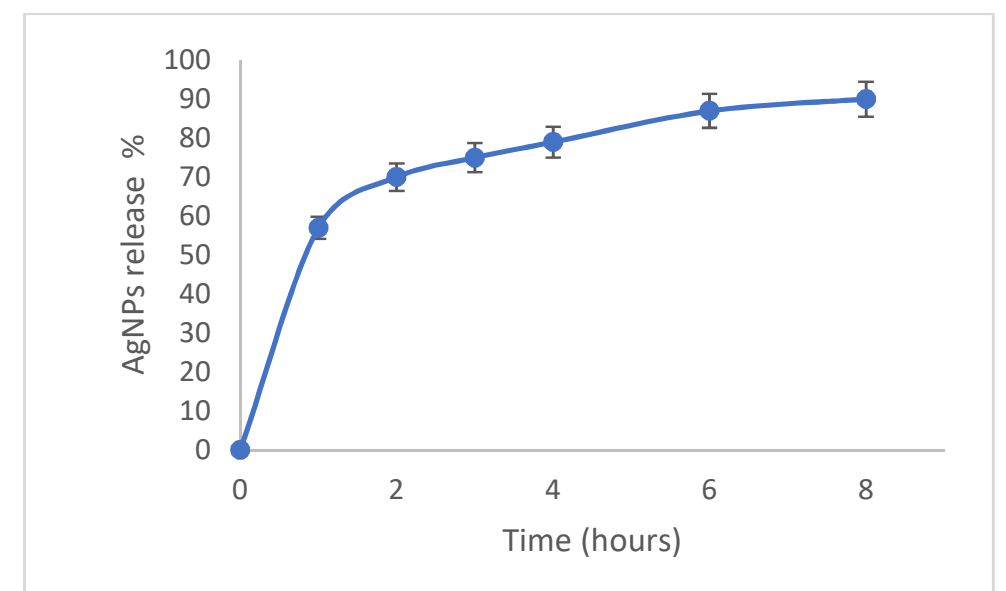

Figure 6: In vitro study release of AgNPs from hydrogel. All results are reported as mean values $\pm \operatorname{SD}(n=3)$.

\section{Wound healing scratch assay}

Wound healing is characterized by several phases such as homeostasis, inflammation, proliferation and remodeling which occur thanks to the activity of several cell types such as keratinocytes, fibroblasts and progenitor cells [19]. The cellular and molecular events that involve wound healing process are chemokines, growth factors, interleukins and cytokines that allow interactions cells to cells and between cells and extracellular matrix (ECM) [38]. The in vitro wound healing activity of HyDrO-DiAb was performed on 3T3 fibroblast cells. As it can be seen from Figure 7, after 24 hours of treatment of cells with the amount of 100 $\mu \mathrm{g} / \mathrm{ml}$ of hydrogel, the wound closure percentage was $75 \pm 0.3 \%$. 

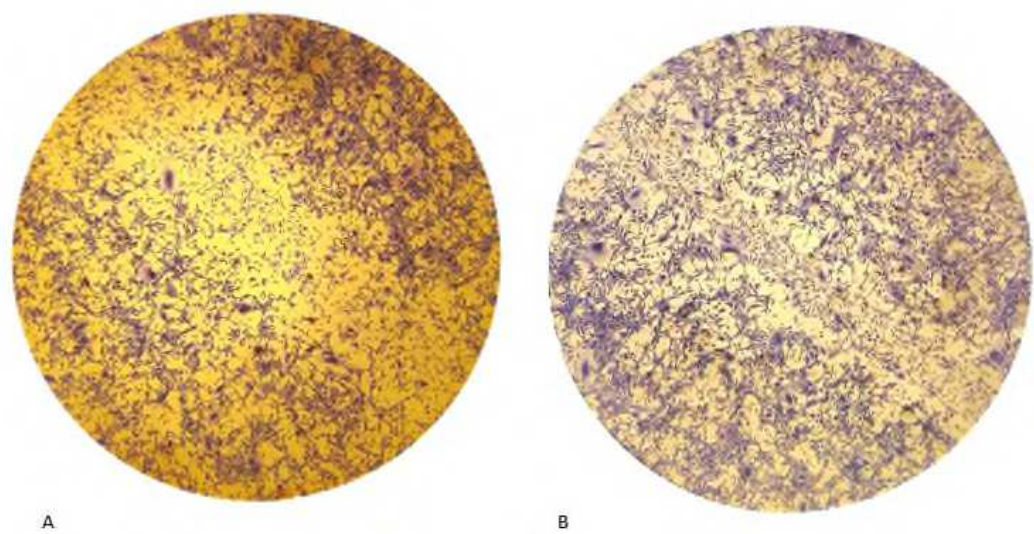

Figure 7: Wound healing activity of HyDrO-DiAb on $3 \mathrm{~T} 3$ fibroblast cells by scratch method (A) and evaluated after 24 hours (B).

The obtained results evidenced that the tested HyDrO-DiAb could affect positively the wound healing process. As already reported, this wound healing process could be ascribable to the antibacterial activity of silver nanoparticles which are able to modulate cytokine and to mitigate inflammation processes [39].

\section{Minimum Inhibitory Concentration (MIC)}

The in vitro antibacterial activity of HyDrO-DiAb was checked against S. aureus, E. coli and P. aeruginosa by using microdilution method and the obtained results were reported as Minimum Inhibitory Concentration (MIC). MIC values for HyDrO-DiAb against E.coli, S. aureus and P. Aeruginosa were $5.15 \mu \mathrm{g} / \mathrm{mL}, 30 \mu \mathrm{g} / \mathrm{mL}$ and $27 \mu \mathrm{g} / \mathrm{mL}$ respectively.

When AgNPs enter in contact with moisture or wound fluid of the wound surface get oxidize and release $\mathrm{Ag}^{+}$ ions which exercise antibacterial activity in three ways: interact with sulfur containing proteins of bacterial cell membrane causing its damage; enter inside the bacteria causing DNA disruption; attack the bacterial respiratory chain causing inhibition of cell division and cell death [11].

\section{In vitro antioxidant and antiinflammatory activity of HyDrO-DiAb}

The inflammatory phase of chronic wound healing is characterized by the production of oxygen species (ROS) by immune cells which, doing this, provide a defense against microorganism. However, in a chronic wound, the overexpression of ROS causes damage in ECM and cells [40] with a consequent delay of wound healing. For this reason, is very important to reduce ROS. The radical scavenging ability of HyDrO-DiAb was assessed by ABTS and DPPH assays and the obtained results were compared to those obtained by a hydrogel composed only by CMC. The obtained data evidenced that HyDrO-DiAb shows a radical scavenging activity above $91 \%$ and $83 \%$ for ABTS and DPPH radical, respectively (Figure 8). Hydrogel composed only by CMC presents a lower radical scavenging activity (Figure 8), probably due to the absence of AgNPs. Antioxidant components of Cs-OLE extract, which were used for green synthesis of nanoparticles, probably influenced the reducing capacity of AgNPs and, so, maybe not all phenolic compounds of the extract have been oxidized to form NPs. This hypothesis was confirmed by evaluating the amount of phenolic compounds which remain in nanoparticles after reduction reaction with $\mathrm{AgNO}_{3}$ (previously reported). 


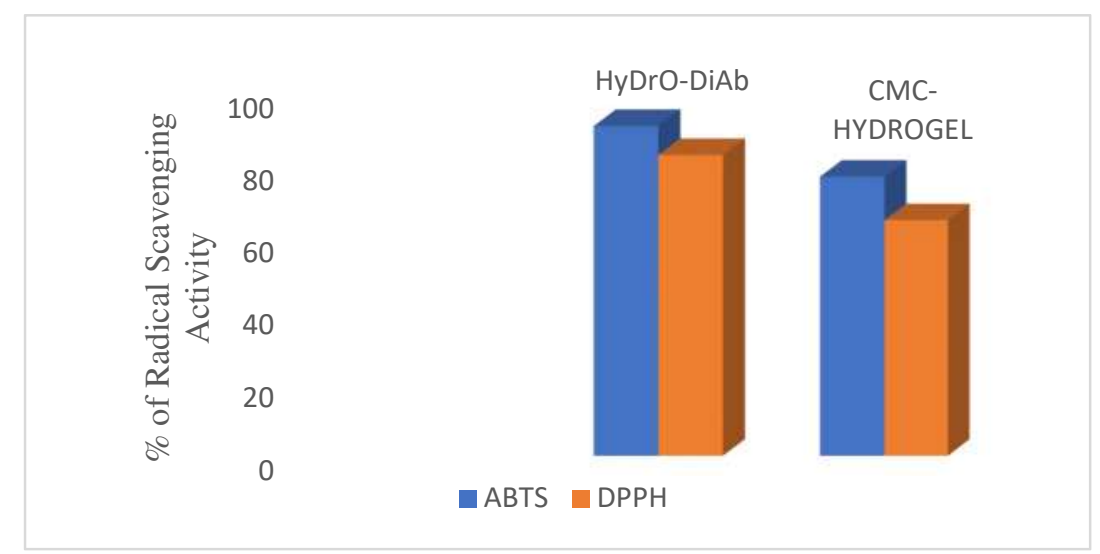

Figure 8: Radical Scavenging Activity of HyDrO-DiAb and CMC-hydrogel. All results are reported as mean values $\pm \operatorname{SD}(n=3)$.

It is well known that denaturation of tissue proteins, which lose their secondary, tertiary and quaternary structure, leads to inflammatory disease [41]. So, tissue protein denaturation becomes a marker for inflammatory state. For this reason, the anti-inflammatory activity of the obtained hydrogel was carried out by estimating its capacity to prevent BSA denaturation. The tested hydrogel showed a good percentage of inhibition $(53 \pm 0.6 \%)$ if compared with that manifested by CMC hydrogel $(27 \pm 0.3 \%)$. The obtained results confirmed the anti-inflammatory activity of HyDrO-DiAb that, with its antibacterial activity, becomes a potential dressing that could be used for the treatment of inflammatory state present in the chronic wound site like DFUs.

\section{In ex-vivo ability to inhibit wound enzymes}

In the aim to evaluate the ability of HyDrO-DiAb to improve wound healing process, its ability to inhibit MPO and Collagenase was tested. Indeed, these enzymes are considered a potential therapeutic target because they are present in high levels in chronic wounds sites.

In the first host immune defense of humans, polymorphonuclear neutrophils are activated and produce MPO which is able to generate hypochlorous acid $(\mathrm{HClO})$ and to neutralize invading microorganisms [24]. $\mathrm{HClO}$ is the most potent bactericidal agent produced in human that, if it is produced in higher quantities, can oxidize different biomolecules and inhibit wound healing process [42]. Furthermore, the inhibition of metalloproteinases, such as collagenase, is an important factor in wound repair because, if they are present in the exudate cause an excessive degradation of ECM [43]. Collagenase, indeed, is responsible of hydrolysis of triple helical regions of collagen and, consequently, causes the loss of activity of this protein which, under physiological conditions, contributes to the reconstruction of damaged tissues. The MPO and collagenase inhibition of HyDrO-DiAb was in ex-vivo evaluated by using venous leg ulcer exudates.

The obtained results (Figure 9) showed a residual activity of collagenase of $27 \pm 0.5 \%$. These data underline that HyDrO-DiAb could be used for the treatment of chronic wounds like DFUs, because inhibits collagenase activity of $73 \pm 0.3 \%$, in ex-vivo. This important activity of hydrogel could be related to its ability to absorb wound exudate that, consequently, causes a reduction of collagenase activity. At the same time, the presence of phenolic compounds in AgNPs can induce conformational changes in the secondary structure of collagenase and, so, inhibit its activity. Furthermore, the tested HyDrO-DiAb is able to reduce the activity of MPO of 84 $\pm 0.5 \%$ (Figure 9). Most probably, this strong inhibition activity of tested hydrogel was due to the burst release of AgNPs in the first 2 hours which evidenced high antioxidant activity and, so, a scavenge property against radical and non-radical species such as $\mathrm{HClO}$.

The obtained results confirmed that the application of HyDrO-DiAb seems to be a promising approach in the wound healing treatment because it is able to reduce MPO and collagenase activity, which are responsible of oxidation of biomolecules and excessive degradation of ECM, respectively. 


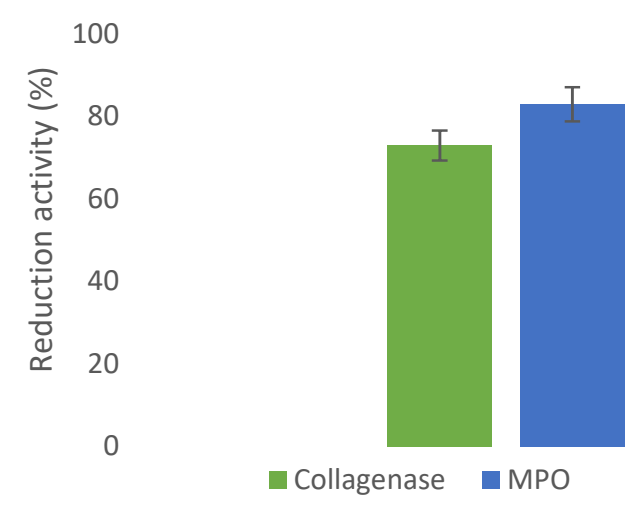

Figure 9: In ex vivo ability of HyDrO-DiAb to inhibit Collagenase and MPO activity.

All results are reported as mean values \pm SD $(n=3)$

\section{Cell viability assay}

The evaluation of cytotoxicity of a hydrogel that should be used as a dressing for chronic and infected wounds, is an important consideration. The biocompatibility of hydrogel was evaluated by using $3 \mathrm{~T} 3$ fibroblast cells because they act as producer of growth factors, which control cell growth and differentiation. For this reason, is very important to minimize the loss of function of fibroblasts by using a biocompatible material [44].

The obtained results indicated that hydrogel exhibited low toxicity to cell fibroblasts. 3T3 fibroblast cells showed $88-97 \%$ of viability after 24 hours of incubation with tested hydrogel. Since the decrease in fibroblast viability for tested sample did not reach $20 \%$, is possible to confirm that prepared hydrogel presented good biocompatibility profile for chronic wound treatment. Figure 10 presents results of toxicity tests of HyDrO$\mathrm{DiAb}$, which was tested at different concentrations.

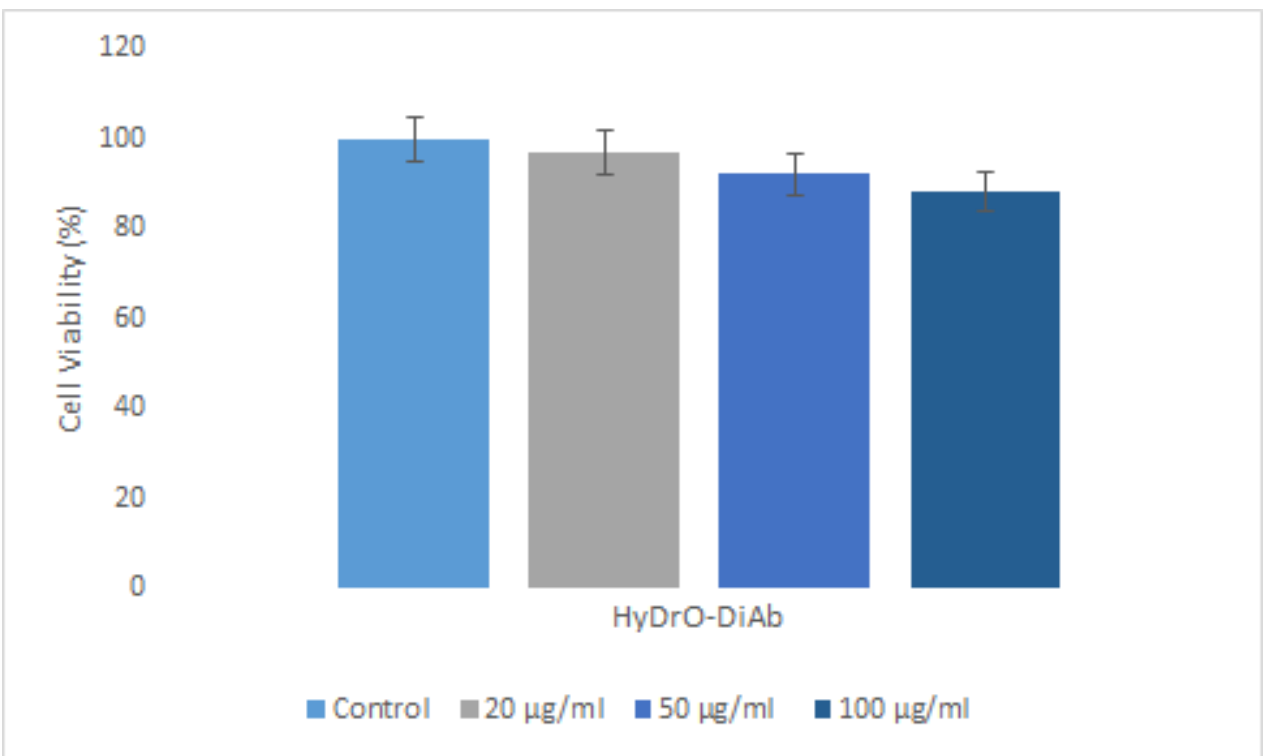

Figure 10: Viability of $3 \mathrm{~T} 3$ fibroblasts cells after 24 hours of incubation at $37^{\circ} \mathrm{C}$ with HyDrO-DiAb. All results are reported as mean values $\pm \mathrm{SD}(\mathrm{n}=3)$

\section{Determination of in vitro skin sensitization}

The h-CLAT test was used to evaluate if tested hydrogel HyDrO-DiAb is a skin sensitizer or non-sensitizer. To predict sensitization of tested sample, RFI \% values of CD86 and CD54 were considered. Indeed, if the 
RFI \% value of CD86 is $\geq 150 \%$ and/or if the RFI\% value of CD54 is $\geq 200 \%$ in at least two independent runs, the sensitization prediction is considered as positive. On the other side, if the RFI \% value of CD86 is <150\% and/or if the RFI\% value of CD54 is $<200 \%$, the sensitization prediction is considered as negative. The guideline reports a protocol divided into different steps. After an initial control on the reactivity of THP-1 cells (reactivity check), the dose finding assay is used to define the concentration range to be used for the evaluation of CD54 and CD86 expression levels. THP-1 cells were exposed to tested HyDrO-DiAb for $24 \mathrm{~h}$ and, to evaluate CV75, PI uptake was evaluated by flow cytometry. The obtained results, reported in Figure 11, confirmed that tested sample is not skin sensitizer.

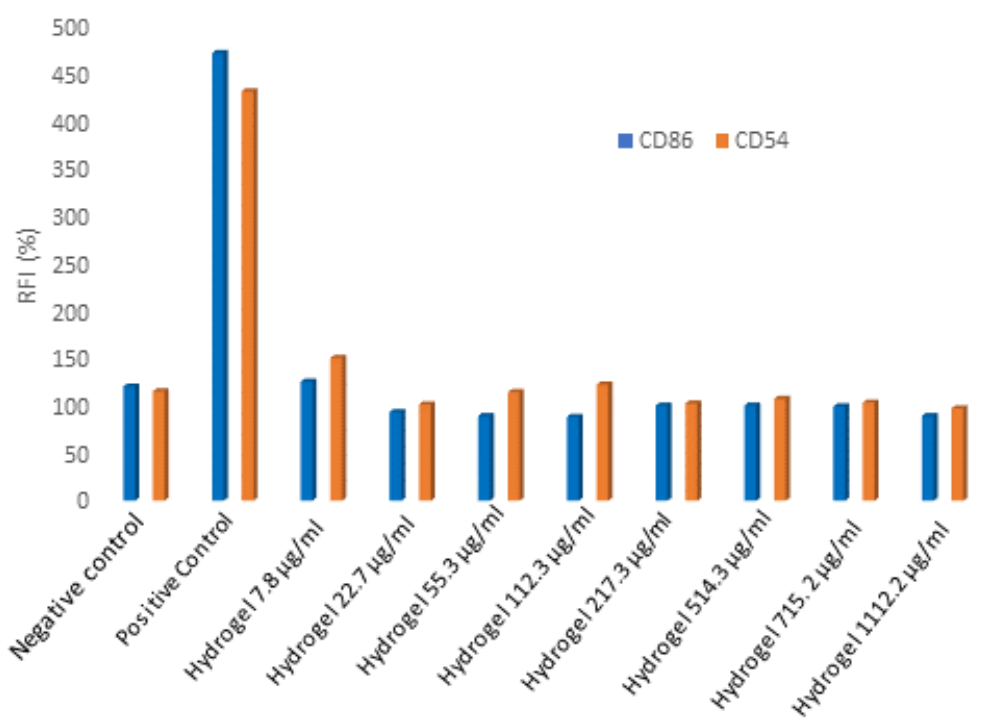

Figure 11: Expression of CD86 and CD54 after treatment with HyDrO-DiAb.

\section{Determination of in vitro skin irritation}

When a test substance, that is applicated on the skin for up to 4 hours, produces a reversible damage to the skin, this substance is considered irritant for the skin [45]. On the basis of the guidelines of the Organization for Economic Cooperation and Development (OECD TG431 and TG439), MTT (viability) on RhE model, was used to in vitro evaluate if tested hydrogel was skin irritant or corrosive. The MTT assay was used to evaluate the activity of mitochondrial reductase which predicts cell viability. In the aim to study skin irritation of tested sample in an accurate and reliable way, HyDrO-DiAb was added to the apical side of the EpiDerm ${ }^{\mathrm{TM}} \mathrm{RhE}$ issues. These 3D tissues were largely used because highly sensitive, in fact, the permeability of their nonviable stratum corneum is 5-200-fold greater than normal human skin [46]. HyDrO-DiAb was tested in this study and the percentages of EpiDerm ${ }^{\mathrm{TM}}$ cell viability, after exposure to sample and controls, were over 50\%, indicating that tested sample was non-irritant, compared with 5\% SDS (positive control), which showed strong irritancy.

\section{Conclusions}

The prepared hydrogel loaded with AgNPs (HyDrO-DiAb) provided a good swelling ability and water retention capacity and, so, the addition of green-synthetized AgNPs to the hydrogel of CMC does not modified the hydrophilic nature of biopolymer. Moreover, HyDrO-DiAb can work as a carrier of AgNPs because, the obtained release results showed that nanoparticles were released in a slow and sustained manner for 8 hours. Scratch test assay revealed that, after 24 hours of treatment of cells with the amount of $100 \mu \mathrm{g} / \mathrm{ml}$ of hydrogel, the wound closure percentage was $75 \pm 0.3 \%$ and, so, the obtained hydrogel could affect positively the wound healing process. This important activity was confirmed by in ex vivo studies, in which the ability of HyDrO- 
DiAb to inhibit MPO and Collagenase was tested. The obtained data highlighted that HyDrO-DiAb could be used for the treatment of chronic wounds like DFUs, because inhibits Collagenase and MPO activity of $73 \pm$ $0.3 \%$ and $84 \pm 0.5 \%$, respectively. HyDrO-DiAb presents, also, good antioxidant, antiinflammatory and antimicrobial activity and, so, it could be used for the treatment of inflammation and infection present in DFUs. Finally, to evaluate safety of the prepared hydrogel, citotoxicity, skin sensitization and skin irritation were evaluated. The obtained results confirmed safety and biocompatibility of HyDrO-DiAb.

\section{Ethics approval and consent to participate}

Not applicable

\section{Consent for publication}

Not applicable

\section{Availability of data and materials}

Not applicable

\section{Competing interests}

Not applicable

\section{Funding}

This research received no external funding.

\section{Authors' contributions}

F.P. and V.P. conceived and designed the experiments; M.R., R.M., M.D. and F. Patitucci performed the experiments; F.P, O.I.P and T.T supervised the experiments; M.R. wrote the manuscript.

\section{Acknowledgements:}

This research was supported by MIUR (PON RI 2014-2020) in the framework of project Programma Operativo Nazionale FSE-FESR Ricerca e Innovazione 2014-2020, Azione I.1 "Dottorati innovativi a caratterizzazione industriale" - XXXIII Ciclo - a.a. 2017/2018

\section{References}

1. Boyko E, Ahroni J, Cohen V, Nelson K, Heagerty P. Prediction of Diabetic Foot Ulcer Occurrence Using Commonly Available Clinical Information: The Seattle Diabetic Foot Study. Diabetes care. 2006;29:1202-7.

2. Boulton AJM, Vileikyte L, Ragnarson-Tennvall G, Apelqvist J. The global burden of diabetic foot disease. Lancet. 2005;366:1719-24.

3. Falanga V. Wound healing and its impairment in the diabetic foot. Lancet. 2005;366:1736-43.

4. Galkowska H, Wojewodzka U, Olszewski WL. Low recruitment of immune cells with increased expression of endothelial adhesion molecules in margins of the chronic diabetic foot ulcers. Wound Repair Regen. 2005;13:248-54.

5. Harding KG, Jones V, Price P. Topical treatment: which dressing to choose. Diabetes Metab Res Rev. 2000;16 Suppl $1: \mathrm{S} 47-50$.

6. Thomas S, Hay P. Fluid handling properties of hydrogel dressings. Ostomy Wound Manage. 1995;41:54-6, 58-9.

7. Ajji Z, Mirjalili G, Alkhatab A, Dada H. Use of electron beam for the production of hydrogel dressings. Radiation Physics and Chemistry. 2008;77:200-2.

8. Barbucci R, Magnani A, Consumi M. Swelling Behavior of Carboxymethylcellulose Hydrogels in Relation to CrossLinking, pH, and Charge Density. Macromolecules. American Chemical Society; 2000;33:7475-80. 
9. Brandt O, Mildner M, Egger AE, Groessl M, Rix U, Posch M, et al. Nanoscalic silver possesses broad-spectrum antimicrobial activities and exhibits fewer toxicological side effects than silver sulfadiazine. Nanomedicine. 2012;8:47888.

10. Percival SL, Bowler PG, Dolman J. Antimicrobial activity of silver-containing dressings on wound microorganisms using an in vitro biofilm model. Int Wound J. 2007;4:186-91.

11. Rai M, Yadav A, Gade A. Silver nanoparticles as a new generation of antimicrobials. Biotechnology Advances. 2009;27:76-83.

12. Iravani S, Korbekandi H, Mirmohammadi SV, Zolfaghari B. Synthesis of silver nanoparticles: chemical, physical and biological methods. Res Pharm Sci. 2014;9:385-406.

13. Keat CL, Aziz A, Eid AM, Elmarzugi NA. Biosynthesis of nanoparticles and silver nanoparticles. Bioresources and Bioprocessing. 2015;2:47.

14. Jadhav K, Dhamecha D, Bhattacharya D, Patil M. Green and ecofriendly synthesis of silver nanoparticles: Characterization, biocompatibility studies and gel formulation for treatment of infections in burns. Journal of Photochemistry and Photobiology B: Biology. 2016;155:109-15.

15. Rolim WR, Lamilla C, Pieretti JC, Díaz M, Tortella GR, Cristina Diez M, et al. Comparison of antibacterial and antibiofilm activities of biologically synthesized silver nanoparticles against several bacterial strains of medical interest. Energ Ecol Environ. 2019;4:143-59.

16. Nasar MQ, Khalil AT, Ali M, Shah M, Ayaz M, Shinwari ZK. Phytochemical Analysis, Ephedra Procera C. A. Mey. Mediated Green Synthesis of Silver Nanoparticles, Their Cytotoxic and Antimicrobial Potentials. Medicina. 2019;55:369. 17. Mishra A, Chaudhary N. Study of Povidone Iodine Loaded Hydrogels as Wound Dressing Material. Trends in Biomaterials and Artificial Organs; Vol 23, No 3 (2010). 2010;23.

18. Mekkawy AI, El-Mokhtar MA, Nafady NA, Yousef N, Hamad MA, El-Shanawany SM, et al. In vitro and in vivo evaluation of biologically synthesized silver nanoparticles for topical applications: effect of surface coating and loading into hydrogels. Int J Nanomedicine. 2017;12:759-77.

19. Makvandi P, Ali GW, Della Sala F, Abdel-Fattah WI, Borzacchiello A. Biosynthesis and characterization of antibacterial thermosensitive hydrogels based on corn silk extract, hyaluronic acid and nanosilver for potential wound healing. Carbohydrate Polymers. 2019;223:115023.

20. Ahsan A, Farooq MA. Therapeutic potential of green synthesized silver nanoparticles loaded PVA hydrogel patches for wound healing. Journal of Drug Delivery Science and Technology. 2019;54:101308.

21. Saratale RG, Saratale GD, Ghodake G, Cho S-K, Kadam A, Kumar G, et al. Wheat straw extracted lignin in silver nanoparticles synthesis: Expanding its prophecy towards antineoplastic potency and hydrogen peroxide sensing ability. International Journal of Biological Macromolecules. 2019;128:391-400.

22. Ruffo M, Parisi OI, Amone F, Malivindi R, Gorgoglione D, De Biasio F, et al. Calabrian Goji vs. Chinese Goji: A Comparative Study on Biological Properties. Foods. Multidisciplinary Digital Publishing Institute; 2017;6:30.

23. Sribalan R, Kirubavathi M, Banuppriya G, Padmini V. Synthesis and biological evaluation of new symmetric curcumin derivatives. Bioorganic \& Medicinal Chemistry Letters. 2015;25:4282-6.

24. Stefanov I, Pérez-Rafael S, Hoyo J, Cailloux J, Santana Pérez OO, Hinojosa-Caballero D, et al. Multifunctional Enzymatically Generated Hydrogels for Chronic Wound Application. Biomacromolecules. American Chemical Society; 2017;18:1544-55.

25. Stefanov I, Hinojosa-Caballero D, Maspoch S, Hoyo J, Tzanov T. Enzymatic synthesis of a thiolated chitosan-based wound dressing crosslinked with chicoric acid. Journal of Materials Chemistry B. Royal Society of Chemistry; 2018;6:7943-53.

26. Sudarsan S, Franklin DS, Sakthivel M, Guhanathan S. Non toxic, antibacterial, biodegradable hydrogels with $\mathrm{pH}-$ stimuli sensitivity: Investigation of swelling parameters. Carbohydrate Polymers. 2016;148:206-15.

27. Kim H, Choi J, Lee H, Park J, Yoon B-I, Jin SM, et al. Skin Corrosion and Irritation Test of Nanoparticles Using Reconstructed Three-Dimensional Human Skin Model, EpiDerm ${ }^{\mathrm{TM}}$. Toxicol Res. 2016;32:311-6.

28. Cabrera C, Artacho R, Giménez R. Beneficial Effects of Green Tea-A Review. Journal of the American College of Nutrition. Taylor \& Francis; 2006;25:79-99.

29. Chen Y, Zhou Y, Zeng L, Dong F, Tu Y, Yang Z. Occurrence of Functional Molecules in the Flowers of Tea (Camellia sinensis) Plants: Evidence for a Second Resource. Molecules. Multidisciplinary Digital Publishing Institute; $2018 ; 23: 790$. 30. Beneficial Effects of Green Tea-A Review: Journal of the American College of Nutrition: Vol 25, No 2 [Internet]. [cited 2021 May 31]. Available from: https://www.tandfonline.com/doi/abs/10.1080/07315724.2006.10719518

31. Donna LD, Mazzotti F, Salerno R, Tagarelli A, Taverna D, Sindona G. Characterization of new phenolic compounds from leaves of Olea europaea L. by high-resolution tandem mass spectrometry. Rapid Communications in Mass Spectrometry. 2007;21:3653-7.

32. Machado S, Pinto SL, Grosso JP, Nouws HPA, Albergaria JT, Delerue-Matos C. Green production of zero-valent iron nanoparticles using tree leaf extracts. Science of The Total Environment. 2013;445-446:1-8.

33. Montazer M, Shamei A, Alimohammadi F. Stabilized nanosilver loaded nylon knitted fabric using BTCA without yellowing. Progress in Organic Coatings. 2012;74:270-6.

34. Bindhu MR, Umadevi M. Synthesis of monodispersed silver nanoparticles using Hibiscus cannabinus leaf extract and its antimicrobial activity. Spectrochimica Acta Part A: Molecular and Biomolecular Spectroscopy. 2013;101:184-90. 
35. Mohan YM, Premkumar T, Lee K, Geckeler KE. Fabrication of Silver Nanoparticles in Hydrogel Networks. Macromolecular Rapid Communications. 2006;27:1346-54.

36. Boroumand MN, Montazer M, Barani H. Biocompatible Stabilize Silver Nanoparticles and Their Antimicrobial Activity. Advanced Science Letters. 2016;22:616-21.

37. Powers JG, Morton LM, Phillips TJ. Dressings for chronic wounds. Dermatologic Therapy. 2013;26:197-206.

38. Hamdan S, Pastar I, Drakulich S, Dikici E, Tomic-Canic M, Deo S, et al. Nanotechnology-Driven Therapeutic Interventions in Wound Healing: Potential Uses and Applications. ACS Cent Sci. American Chemical Society; 2017;3:163-75.

39. Liu X, Lee P, Ho C, Lui VCH, Chen Y, Che C, et al. Silver Nanoparticles Mediate Differential Responses in Keratinocytes and Fibroblasts during Skin Wound Healing. ChemMedChem. 2010;5:468-75.

40. Frykberg RG, Banks J. Challenges in the Treatment of Chronic Wounds. Advances in Wound Care. Mary Ann Liebert, Inc., publishers; 2015;4:560-82.

41. Opie EL. ON THE RELATION OF NECROSIS AND INFLAMMATION TO DENATURATION OF PROTEINS. J Exp Med. 1962;115:597-608.

42. Klebanoff SJ. Myeloperoxidase: friend and foe. Journal of Leukocyte Biology. 2005;77:598-625.

43. Gibson DJ, Schultz GS. Molecular Wound Assessments: Matrix Metalloproteinases. Advances in Wound Care. Mary Ann Liebert, Inc., publishers; 2012;2:18-23.

44. Hannan RT, Peirce SM, Barker TH. Fibroblasts: Diverse Cells Critical to Biomaterials Integration. ACS Biomater Sci Eng. American Chemical Society; 2018;4:1223-32.

45. Winder C, Azzi R, Wagner D. The development of the globally harmonized system (GHS) of classification and labelling of hazardous chemicals. Journal of Hazardous Materials. 2005;125:29-44.

46. Perkins MA, Osborne R, Rana FR, Ghassemi A, Robinson MK. Comparison of in vitro and in vivo human skin responses to consumer products and ingredients with a range of irritancy potential. Toxicological Sciences. 1999;48:21829. 